\title{
Advanced Materials \\ Responsive double network hydrogels of interpenetrating DNA and CB[8] host-guest supramolecular systems \\ --Manuscript Draft--
}

\begin{tabular}{|c|c|}
\hline Manuscript Number: & adma.201501102R1 \\
\hline Full Title: & $\begin{array}{l}\text { Responsive double network hydrogels of interpenetrating DNA and } \mathrm{CB}[8] \text { host-guest } \\
\text { supramolecular systems }\end{array}$ \\
\hline Article Type: & Communication \\
\hline \multicolumn{2}{|l|}{ Section/Category: } \\
\hline Keywords: & supramolecular double-network; stimuli-responsive; DNA; $\mathrm{CB}[8]$; hydrogels \\
\hline Corresponding Author: & $\begin{array}{l}\text { Dongsheng Liu, Prof. Dr. } \\
\text { Tsinghua University } \\
\text { Beijing, CHINA }\end{array}$ \\
\hline \multicolumn{2}{|l|}{ Additional Information: } \\
\hline Question & Response \\
\hline $\begin{array}{l}\text { Please submit a plain text version of your } \\
\text { cover letter here. } \\
\text { If you are submitting a revision of your } \\
\text { manuscript, please do not overwrite your } \\
\text { original cover letter. There is an } \\
\text { opportunity for you to provide your } \\
\text { responses to the reviewers later; please } \\
\text { do not add them here. }\end{array}$ & $\begin{array}{l}\text { Dear Dr. Duoduo Liang, } \\
\text { Manuscript number: adma. } 201501102 \\
\text { Title: “Responsive double network hydrogels of interpenetrating DNA and CB[8] host- } \\
\text { guest supramolecular systems”. } \\
\text { Thank you for your email dated } 20 \text { March } 2015 \text { and revision request for our submission } \\
\text { to Advanced Materials. We have carefully considered referees' comments and made } \\
\text { revisions as detailed below. } \\
\text { Thank you very much for your time. } \\
\text { Sincerely, } \\
\text { Professor Dongsheng Liu } \\
\text { Department of Chemistry, Tsinghua University } \\
\text { Beijing 100084, China, Tel.: +86-10-62794081, Fax: +86-10-62796082 } \\
\text { E-mail: liudongsheng@tsinghua.edu.cn }\end{array}$ \\
\hline \multicolumn{2}{|l|}{$\begin{array}{l}\text { Corresponding Author Secondary } \\
\text { Information: }\end{array}$} \\
\hline Corresponding Author's Institution: & Tsinghua University \\
\hline \multicolumn{2}{|l|}{$\begin{array}{l}\text { Corresponding Author's Secondary } \\
\text { Institution: }\end{array}$} \\
\hline First Author: & Chuang Li \\
\hline \multicolumn{2}{|l|}{ First Author Secondary Information: } \\
\hline \multirow[t]{8}{*}{ Order of Authors: } & Chuang Li \\
\hline & Matthew J. Rowland \\
\hline & Yu Shao \\
\hline & Tianyang Cao \\
\hline & Chun Chen \\
\hline & Haoyang Jia \\
\hline & Xu Zhou \\
\hline & Zhongqiang Yang \\
\hline
\end{tabular}


Oren A. Scherman

Dongsheng Liu, Prof. Dr.

Order of Authors Secondary Information:

Abstract:

A supramolecular double network hydrogel is presented here by physical interpenetration of DNA and $\mathrm{CB}[8]$ networks. In addition to exhibiting an increase in strength and thermal stability, the double network hydrogel possesses excellent properties such as stretchability, ductility, shear-thinning and thixotropy. Moreover, it is enzymatically responsive to both nuclease and cellulase as well as small molecules, showing great potential as a new soft material scaffold. 


\section{WILEY-VCH}

DOI: $10.1002 /(($ please add manuscript number $))$

Article type: Communication

\section{Responsive double network hydrogels of interpenetrating DNA and CB[8] host-guest supramolecular systems}

Chuang Li,$^{\dagger \S}$ Matthew J. Rowland,$^{\ddagger \S}$ Yu Shao, ${ }^{\dagger}$ Tianyang Cao ${ }^{\dagger}$ Chun Chen,${ }^{\dagger}$ Haoyang Jia,$^{\dagger}$ Xu Zhou, ${ }^{\dagger}$ Zhongqiang Yang, ${ }^{\dagger}$ Oren A. Scherman ${ }^{* \star}$ and Dongsheng Liu ${ }^{* \dagger}$

((Optional Dedication))

${ }^{\dagger}$ C. Li, Y. Shao, T. Y. Cao, C. Chen, H. Y. Jia, X. Zhou, Dr. Z. Q. Yang, Prof. D. S. Liu Key Laboratory of Organic Optoelectronics \& Molecular Engineering of the Ministry of Education, Department of Chemistry, Tsinghua University, Beijing, 100084, China E-mail: E-mail: liudongsheng@tsinghua.edu.cn

${ }^{\ddagger}$ M. J. Rowland, Prof. O. A. Scherman

Melville Laboratory for Polymer Synthesis, Department of Chemistry, University of Cambridge, Cambridge, CB2 1EW, UK

E-mail: oas23@cam.ac.uk

${ }^{\S}$ These authors contributed equally to this work

Keywords: supramolecular double-network, stimuli-responsive, DNA, CB[8], hydrogels 


\section{WILEY-VCH}

Hybrid hydrogels are particularly important in materials science as they can be formulated to closely exhibit the combined physical properties of individual components and offer opportunities to selectively tailor material properties. ${ }^{[1]}$ One early and important example of this field is interpenetrating polymer networks (IPNs), which was introduced in the 1960s. ${ }^{[2]}$ Based on this concept, in 2003 Gong and coworkers developed materials called double network gels, and reported an innovative and universal pathway to fabricate gels with extremely high mechanical performance which can be tailored to mimic a wide variety of load-bearing biological tissue, ranging from "soft" tissue such as muscle to firmer tissue such as bone. ${ }^{[3]}$ Generally, double networks consist of two individual chemically cross-linked networks with contrasting physical properties: one network as a rigid skeleton (the first network) and a second network as a soft and ductile substance. ${ }^{[4]}$ Interpenetration of these two networks with good homogeneity results in a non-linear increase in mechanical strength and resistance to fracture, often much greater than calculated values models would predict. The enhanced mechanical strength exhibited by such hydrogels is likely attributed to the stresstransfer between the two interpenetrating networks, instead of the stress being confined to the smallest cross-link of a single component gel. ${ }^{[5]}$ However, current double network hydrogels are mostly based on fully or partially chemically cross-linked networks, ${ }^{[6]}$ and the effect of replacing chemical cross-links for physical cross-links in such materials has not yet been studied. It is of great interest to examine the formation of double network hydrogels from non-covalent supramolecular systems as such materials will afford the ability to regulate cross-link dynamics and respond to a variety of external stimuli. ${ }^{[7]}$

Herein we present the first example of an entirely self-assembling and supramolecular double network hydrogel, which is formed from the combination of two distinctly different hydrogel systems: one through DNA hybridization, ${ }^{[8]}$ and the other by host-guest interactions of cucurbit[8]uril (CB[8]). ${ }^{[9]}$ Merging these two hydrogel formulations accesses a new material 


\section{WILEY-VCH}

comprised of two interpenetrating networks that have no cross-linking interactions with each other. Unlike the formation process of chemically cross-linked double network hydrogels via a two-step polymerization, our supramolecular system can be fabricated by a simple "onepot" mixing method attributed to the highly precise and specific recognition motifs. Figure 1 illustrates our strategy to which there are four fundamental components: DNA Y-scaffold, DNA linker, phenylalanine-functionalized carboxymethyl cellulose (CMC-phe) and CB[8]. The DNA Y-scaffold and DNA linker can distinctly bind each other on account of the precise hybridization of complementary DNA sequences to form the first cross-linked hydrogel network, referred to as DNA hydrogel. ${ }^{[10]}$ Alternatively, CMC-phe and $\mathrm{CB}[8]$ can also specifically recognize each other owing to the host-guest interaction between phenylalanine and $\mathrm{CB}[8]$ to form the second cross-linked hydrogel network, referred to hereon as $\mathrm{CB}[8]$ hydrogel. ${ }^{[11]}$ Upon combining these four components in PBS buffer (100mM, pH 7.4) via a "one-pot" mixing method, the corresponding units recognize one another, resulting in two interpenetrating supramolecularly-assembled networks, namely a double network hydrogel. Notably, combining these two systems is of particular interest as they exhibit very different mechanical properties. For example, the DNA hydrogel has a very low $\tan \delta\left(\mathrm{G}^{\prime} / \mathrm{G}^{\prime}\right)$ but is brittle, whereas the $\mathrm{CB}[8]$ hydrogel has a higher $\tan \delta$ but is less susceptible to breakage. Our aim was to design a material of high modulus (on account of dual interpenetrating networks) whilst retaining or enhancing the most desirable properties of each single network. Furthermore, the resulting double network hydrogel would possess a full biodegradability profile as each single network can be selectively digested by specific enzymes, i.e. nuclease degradation of the DNA network and cellulase cleave of the $\mathrm{CB}[8]$ network. This allows for the selective degradation of one network whilst retaining the structure and mechanical property of the remaining single network. This prospect is particularly exciting as it potentially has application in enzymatically-triggered response from a pre-selected network 


\section{WILEY-VCH}

whilst retaining the hydrogel architecture and structure through the persistence of the remaining other. ${ }^{[12]}$

Each single and double network hydrogel formulation was prepared in phosphate-buffered saline (PBS, 100mM, pH 7.4) with a mass content of each single network of $1.5 \mathrm{wt} \%$. As shown in Figure 2A, the freshly prepared CB[8] hydrogel is slightly turbid whereas the DNA hydrogel is optically transparent. The resultant double network hydrogel maintains an intermediate almost transparent state between the two corresponding independent networks. The differences in mechanical properties between the double network hydrogel and corresponding single network hydrogel formulations were also studied. As demonstrated in Figures 2B and S1, the separate addition of either CB[8] or CMC-phe components into the $1.5 \mathrm{wt} \%$ DNA hydrogel have little influence on the mechanical property of the DNA hydrogel. However, upon simultaneous addition of $\mathrm{CB}[8]$ and CMC-phe to the DNA hydrogel to form the double network hydrogel, the G' increased from $80 \pm 1.6 \mathrm{~Pa}$ to $281 \pm 2.4 \mathrm{~Pa}$ (also see Figure S2A), which is higher than the sum of the two single network hydrogels (calculated double hydrogel, $230 \pm 3.4 \mathrm{~Pa}$ ). These results indicated that the two interpenetrating networks indeed increased the mechanical property of the double network hydrogel beyond the expected value; however, there is no increase in the order of magnitude of the modulus as previously demonstrated with chemically crosslinked hydrogels. ${ }^{[3 a]}$ This difference can be attributed to the relatively weak interactions of supramolecular non-covalent cross-linking compared to stronger covalent conjugation, as the two networks experience stress, the physical cross-links can be easily sheared. Interestingly, the internal supramolecular network structure appears responsive to increasing applied stretching frequency, similar to the $\mathrm{CB}[8]$ hydrogel and unlike the DNA hydrogel, implying the $\mathrm{CB}[8]$ hydrogel dominates the macroscopic structuring and viscoelastic response, Figure S2B. A further study of the thermal behavior was also performed, during which G' decreases with an increase in temperature and 


\section{WILEY-VCH}

intersects with G" at the gel-sol transition point. As shown in Figure $\mathbf{2 C}$, the transition temperatures of the DNA hydrogel and the $\mathrm{CB}[8]$ hydrogel were $51 \pm 0.5^{\circ} \mathrm{C}$ and $46 \pm 0.8^{\circ} \mathrm{C}$, respectively. However, the double network hydrogel impressively exhibited a higher gel-sol transition point at $62 \pm 1.2{ }^{\circ} \mathrm{C}$, again demonstrating that the two interpenetrating networks strengthened the thermal stability of the double network hydrogel. It was found that with an increase in mass content from 1.0 to $2.0 \mathrm{wt} \%$, the G' of double network hydrogel increased from 103.6 $\pm 1.6 \mathrm{~Pa}$ to $510.9 \pm 4.0 \mathrm{~Pa}$, and the value of $\tan \delta$ decreased from $0.48 \pm 0.015$ to $0.38 \pm 0.010$ (Figure 2D), demonstrating that higher mass content affords higher G' values, and therefore stronger double network hydrogels. These results also demonstrated that the double network hydrogel possesses an increased mechanical strength due to the interpenetrating interactions and it is very simple process to tune the mechanical strength by tailoring the mass contents.

DNA hydrogels are cross-linked through hybridization of "sticky ends" between the DNA Yscaffold and DNA linker. The rigid duplex structures and strong base-pair interactions result in the formation of a material that is relatively brittle. Upon compression, the hydrogels adhere to the testing parallel plate of the rheometer and after rheological analysis could be further stretched to $5233 \%$ (from $150 \mu \mathrm{m}$ to $8000 \mu \mathrm{m}$ ) on retraction of the upper plate, Figure 2E. Specifically, the DNA hydrogels $(1.5 \mathrm{wt} \%, 40 \mu \mathrm{L})$ exhibited a "narrow neck" during the stretching process followed by fracture (Supporting information Figure S3); moreover, they tended to lose their adherence to the top plate when stretched beyond $8 \mathrm{~mm}$. Alternatively, $\mathrm{CB}[8]$ hydrogels $(1.5 \mathrm{wt} \%, 40 \mu \mathrm{L})$ could readily be stretched to $8 \mathrm{~mm}$ without expressing a narrow neck (middle in Figure 2E) or as long as $2 \mathrm{~cm}$ when manipulated with tweezers before fracture (Figure S4), on account of the flexible polymer chains and the reconfiguration of the $\mathrm{CB}[8]$ cross-links offsetting any induced strain from the stretching process. Interestingly, the double network hydrogel $(1.5 \mathrm{wt} \%, 40 \mu \mathrm{L})$ overcame the brittleness of the pure DNA 


\section{WILEY-VCH}

demonstrated the good stretching properties inherent of the $\mathrm{CB}[8]$ hydrogel whilst maintaining shape persistence and rigidity of the DNA hydrogel, combined effects of the two interpenetrating non-covalent networks possessing dramatically different properties. Thus, the double network hydrogel exhibits truly emergent behavior upon deformation. This double network hydrogel could therefore be an ideal system to build a theoretical mechanics model to explain how force is transferred between rigid and flexible networks and this work is ongoing. We further investigated the stretching behavior of the double network hydrogel through manipulation with tweezers, Figure $\mathbf{2 F}$, and found that the hydrogels can be stretched uniformly up to $2 \mathrm{~cm}$ without expressing a narrow neck, or as far as $3 \mathrm{~cm}$ without fracturing (Figure S5) and the compressing/stretching process can be cycled for three times with good reversibility (Figure S6). These observations also indicated that our double network hydrogel can overcome the brittleness of DNA hydrogels and retain the good ductility of $\mathrm{CB}[8]$ hydrogels. ${ }^{[13]}$

To investigate the combined behavior of the two interpenetrating networks, fluorescence labeling of the individual networks and confocal microscopy was undertaken. As shown in Figure 3A, pure DNA hydrogel networks were stained by the intercalating nucleic acidspecific dye GelGreen ${ }^{\mathrm{TM}}$ and exhibited uniform green color, indicating uniformity of the network. Alternatively, rhodamine isothiocyanate was chemically conjugated onto the CMC backbone. As shown in Figure 3B, the CB[8] hydrogel network exhibited red color with a few high density micro-domains, which may be attributed to some small degree of folding of the $\mathrm{CMC}$ backbones or aggregation upon 2:1 complexation with $\mathrm{CB}[8]$. The double network appeared green, red, and orange under the green channel, red channel, and the merged channels respectively. As shown in Figure 3C (merged channels), the two network components are physically interpenetrating and bound within each other. This kind of binding behavior is the potential reason for observing strengthened mechanical properties and 


\section{WILEY-VCH}

increased thermal stability as described in Figure 2. To further clarify the microstructure of the interpenetrating networks, scanning electron microscopy (SEM) was also used to investigate the detailed morphologies of lyophilized hydrogels. As shown in Figure 3, owing to the rigidity and helicity of double stranded DNA, the lyophilized DNA hydrogel (1.5 wt $\%$ ) resulted in networks with smaller pores on the scale of tens of microns and thicker walls on the scale of several microns. On the contrary, the lyophilized $\mathrm{CB}[8]$ hydrogel $(1.5 \mathrm{wt} \%)$ exhibited larger pores and thinner walls than that of the DNA hydrogel, likely attributed to the large flexibility of CMC polymers. Interestingly, the resultant double network hydrogel resulted in an intermediate morphology with a pore size similar to the DNA hydrogel and wall thickness close to the $\mathrm{CB}[8]$ hydrogel. This different morphology further verifies that the two network components are physically interpenetrating and bound within each other on the microscopic scale, altering the network structure, which in turn contributes to the overall properties on the macroscopic scale.

As DNA hybridization and host-guest interactions between $\mathrm{CB}[8]$ and phenylalanine are both based on physical supramolecular interactions, the resultant double network hydrogel should exhibit an excellent shear-thinning behavior. ${ }^{[14]}$ This was first studied using steady shear rheology, Figure 4A. Upon increasing the shear rate from 0.001 to $0.01 \mathrm{~s}^{-1}$, the material expressed behavior of a Newtonian fluid as the dynamic viscosity remained constant. Beyond a shear rate of $0.01 \mathrm{~s}^{-1}$ the double hydrogel exhibited non-Newtonian shear thinning behavior and the viscosity dramatically decreased, a property related to plastic flow. The rheological properties of the double network hydrogel were further studied by oscillatory strain dependent rheology across an oscillatory strain range of $0.5-1000 \%$ at a fixed angular frequency of $1 \mathrm{~Hz}$ at $25^{\circ} \mathrm{C}$. As shown in Figure 4B, the G' value rapidly decreased upon reaching $30 \%$ and had a crossing point with G" at $300 \%$, the gel-to-sol transition point, indicating a collapse of the gel state to a quasi-liquid sol state. It was observed that this gel-sol transition of the double 


\section{WILEY-VCH}

network hydrogel was reversible and the quasi-liquid sol state can recover to its original value very rapidly when the strain was reverted from $1000 \%$ back to $1 \%$, Figure 4 C. Upon the application of a large amplitude oscillatory strain (1000\%), the $G^{\prime}$ value sharply decreased and became instantaneously lower than G". The system persists at this quasi-liquid state under $1000 \%$ oscillation strain. When the applied strain was returned to $1 \%$, both G' and G" were fully recovered without delay or fatigue and this process was recyclable. These results demonstrate that the double network hydrogels reported here have excellent shear thinning and rapid thixotropic properties, amenable to direct injection through a needle and syringe (Figure S7). We further investigated the thixotropic behavior of the double network hydrogel as shown in Figure 4D, and found that the shear stress increased with an increase of shear rate from $0.01 \mathrm{~s}^{-1}$ to $100 \mathrm{~s}^{-1}$ and vice versa, and the area below encompassed by the hysteresis loop very small indicating very little energy is required for structure breakdown. These results further verified that our double network hydrogel possesses both excellent thixotropic as well as shear-thinning properties, which may find great potential in injectable soft materials and drug delivery applications. ${ }^{[15]}$

Benefiting from the intrinsic properties of biopolymers such as DNA or cellulose, the resultant double network hydrogel exhibited dual-biodegradability profiles to nuclease and cellulase, respectively. As shown in Figure 5A, the double network hydrogel can be digested by EcoR I (restriction endonuclease with digestion site of GAATTC) at room temperature over $24 \mathrm{~h}$, cleaving the DNA network component within the system and leaving the $\mathrm{CB}[8]$ hydrogel network alone with encapsulated DNA fragments. Alternatively, a similar effect can be achieved by addition of cellulase, which can specifically destroy the $\mathrm{CB}[8]$ hydrogel network, leaving the DNA hydrogel network component intact. Additionally, competitive substitution could also be used to selectively destroy one network. For example, adding free phenylalanine (in 5-fold molar excess compared to $\mathrm{CB}[8]$ ) into the double network hydrogel 


\section{WILEY-VCH}

resulted in competition for the interaction between $\mathrm{CB}[8]$ and the grafted phenylalanine on the

CMC backbone. If EcoR I and cellulase are both added into the double network hydrogel simultaneously, full degradation of the system can be realized, resulting in a one-way gel-tosol transition. Furthermore, changes in the mechanical properties were observed by rheology. As shown in Figures 5B and S8, the G' decreased from $276.8 \pm 3.2 \mathrm{~Pa}$ to $160.2 \pm 5.1 \mathrm{~Pa}$ after treatment by EcoR I for $24 \mathrm{~h}$. Similarly, degradation by cellulase for $24 \mathrm{~h}$ caused the mechanical strength to decrease to $70.9 \pm 2.3 \mathrm{~Pa}$, which was exactly consistent with the value of the pure DNA hydrogel. Interestingly, competitive substitution by free phenylalanine also partially destroyed the $\mathrm{CB}[8]$ hydrogel network and lowered the mechanical strength to 106.6 \pm 7.1 Pa. As expected, after incubation with EcoR I and cellulase for $24 \mathrm{~h}$, the double network hydrogel was fully degraded and yielded a mixture that behaved as a solution whereby G' tended to zero. These results demonstrated that our double network hydrogel possesses dualenzymatic as well as small molecule responsiveness, enabling either selective partial or full degradation to meet different requirements for applications such as controlled drug delivery or orthogonal regulation of cell microenvironments. ${ }^{[16]}$

In summary, we demonstrated a responsive double network hydrogel entirely based on supramolecular interactions, i.e. DNA hybridization and host-guest recognition, which is distinctly different from previously reported chemically cross-linked double networks. Fluorescence labeling verified that the individual DNA and $\mathrm{CB}[8]$ networks were physically interpenetrating and bound within each other contributing to the increased mechanical properties and thermal stability. Furthermore, the interpenetrating behavior provides advantages for the double network hydrogel, i.e. excellent stretchability and ductility contributing resistance to fracture. Based on the dynamic and reversible supramolecular interactions, the double network hydrogel possesses shear-thinning and thixotropic properties, which show great potential as injectable soft materials for in vivo applications. Finally, on the 


\section{WILEY-VCH}

account of the natural biodegradability of the DNA and cellulose backbones, the double network hydrogel is responsive to nuclease and cellulase as well as to small molecules. We believe that all of the advantages above make our supramolecular double network hydrogel an excellent new soft material scaffold that can be used in a wide variety of applications including dynamic surface coatings, controlled release and tissue engineering.

\section{Acknowledgements}

We thank the National Basic Research Program of China (973 program, No. 2013CB932803), the National Natural Science Foundation of China (No. 91427302, 21421064), the NSFCDFG joint project TRR61 and Beijing Municipal Science \& Technology Commission for financial support. MJR thanks the University of Cambridge PhD Training Programme in Chemical Biology and Molecular Medicine.

Received: ((will be filled in by the editorial staff))

Revised: ((will be filled in by the editorial staff)) Published online: ((will be filled in by the editorial staff))

[1] a) C. Wang, R. J. Stewart, J. KopeCek, Nature 1999, 397, 417; b) J. Kopeček, J. Yang, Angew. Chem. Int. Ed. 2012, 51, 7396; c) H. K. Lau, K. L. Kiick, Biomacromolecules 2014, $16,28$.

[2] a) L. H. Sperling, V. Mishra, Polym. Adv. Technol. 1996, 7, 197; b) L. H. Sperling, in Encyclopedia of Polymer Science and Technology, John Wiley \& Sons, Inc., 2002.

[3] a) J. P. Gong, Y. Katsuyama, T. Kurokawa, Y. Osada, Adv. Mater. 2003, 15, 1155; b)

J. P. Gong, Science 2014, 344, 161.

[4] a) M. A. Haque, T. Kurokawa, J. P. Gong, Polymer 2012, 53, 1805; b) T. Nakajima, H. Sato, Y. Zhao, S. Kawahara, T. Kurokawa, K. Sugahara, J. P. Gong, Adv. Funct. Mater. 2012, $22,4426$.

[5] a) J. P. Gong, Soft Matter 2010, 6, 2583; M. Shibayama, Soft Matter 2012, 8, 8030; b)

X. Zhao, Soft Matter 2014, 10, 672; c) E. Ducrot, Y. Chen, M. Bulters, R. P. Sijbesma, C. Creton, Science 2014, 344, 186. 


\section{WILEY-VCH}

[6] J.-Y. Sun, X. Zhao, W. R. K. Illeperuma, O. Chaudhuri, K. H. Oh, D. J. Mooney, J. J. Vlassak, Z. Suo, Nature 2012, 489, 133.

[7] a) E. A. Appel, J. del Barrio, X. J. Loh, O. A. Scherman, Chem. Soc. Rev. 2012, 41, 6195; b) X. Yan, F. Wang, B. Zheng, F. Huang, Chem. Soc. Rev. 2012, 41, 6042; c) M.

Burnworth, L. Tang, J. R. Kumpfer, A. J. Duncan, F. L. Beyer, G. L. Fiore, S. J. Rowan, C. Weder, Nature 2011, 472, 334; d) L. E. Buerkle, S. J. Rowan, Chem. Soc. Rev. 2012, 41, 6089;

e) M. M. E. Koenigs, A. Pal, H. Mortazavi, G. M. Pawar, C. Storm, R. P. Sijbesma, Macromolecules 2014, 47, 2712; f) R. Pinalli, E. Dalcanale, Acc. Chem. Res. 2013, 46, 399.

[8] a) Y. Dong, Z. Yang, D. Liu, Acc. Chem. Res. 2014, 47, 1853; b) D. Liu, E. Cheng, Z. Yang, NPG Asia Mater 2011, 3, 109; c) N. C. Seeman, Nature 2003, 421, 427; d) E. Stulz, G. Clever, M. Shionoya, C. Mao, Chem. Soc. Rev. 2011, 40, 5633; e) T. Schnitzler, A. Herrmann, Acc. Chem. Res. 2012, 45, 1419.

[9] a) E. A. Appel, F. Biedermann, U. Rauwald, S. T. Jones, J. M. Zayed, O. A. Scherman, J. Am. Chem. Soc. 2010, 132, 14251; b) Y. Lan, Y. Wu, A. Karas, O. A. Scherman, Angew. Chem. Int. Ed. 2014, 53, 2166; c) M. J. Rowland, E. A. Appel, R. J. Coulston, O. A. Scherman, J. Mater. Chem. B 2013, 1, 2904.

[10] a) S. H. Um, J. B. Lee, N. Park, S. Y. Kwon, C. C. Umbach, D. Luo, Nat. Mater. 2006, 5, 797; b) E. Cheng, Y. Xing, P. Chen, Y. Yang, Y. Sun, D. Zhou, L. Xu, Q. Fan, D. Liu, Angew. Chem. Int. Ed. 2009, 121, 7796; c) B. Wei, I. Cheng, K. Q. Luo, Y. Mi, Angew. Chem. Int. Ed. 2008, 120, 337; d) Z. Zhu, C. Wu, H. Liu, Y. Zou, X. Zhang, H. Kang, C. J. Yang, W. Tan, Angew. Chem. Int. Ed. 2010, 49, 1052; e) Y. Xing, E. Cheng, Y. Yang, P. Chen, T. Zhang, Y. Sun, Z. Yang, D. Liu, Adv. Mater. 2011, 23, 1117; f) J. Liu, Soft Matter 2011, 7, 6757; g) E. Cheng, Y. Li, Z. Yang, Z. Deng, D. Liu, Chem. Commun. 2011, 47, 5545; h) S. Peng, T. L. Derrien, J. Cui, C. Xu, D. Luo, Mater. Today 2012, 15, 190; i) J. Jin, Y. Xing, Y. Xi, X. Liu, T. Zhou, X. Ma, Z. Yang, S. Wang, D. Liu, Adv. Mater. 2013, 25, 4714; j) H. Qi, M. Ghodousi, Y. Du, C. Grun, H. Bae, P. Yin, A. Khademhosseini, Nat. Commun. 2013, 4; k) 


\section{WILEY-VCH}

C. Li, P. Chen, Y. Shao, X. Zhou, Y. Wu, Z. Yang, Z. Li, T. Weil, D. Liu, Small 2014, DOI: 10.1002/smll.201401906; 1) Y. Wu, C. Li, F. Boldt, Y. Wang, S. L. Kuan, T. T. Tran, V.

Mikhalevich, C. Fortsch, H. Barth, Z. Yang, D. Liu, T. Weil, Chem. Commun. 2014, 50, 14620; m) C. Li, A. F-Jones, A. R. Dun, J. Jin, P. Chen, Y. Xing, Z. Yang, Z. Li, W. Shu, D. Liu, R. R. Duncan, Angew. Chem. Int. Ed. 2015, DOI: 10.1002/anie.201411383R1; n) Z. Zhu, Z. Guan, S. Jia, Z. Lei, S. Lin, H. Zhang, Y. Ma, Z.-Q. Tian, C. J. Yang, Angew. Chem. Int. Ed. 2014, 126, 12711.

[11] a) E. A. Appel, X. J. Loh, S. T. Jones, F. Biedermann, C. A. Dreiss, O. A. Scherman, J. Am. Chem. Soc. 2012, 134, 11767; b) E. A. Appel, X. J. Loh, S. T. Jones, C. A. Dreiss, O. A. Scherman, Biomaterials 2012, 33, 4646.

[12] a) Y.-C. Chiu, J. C. Larson, V. H. Perez-Luna, E. M. Brey, Chem. Mater. 2009, 21, 1677; b) L. A. Hockaday, K. H. Kang, N. W. Colangelo, P. Y. C. Cheung, B. Duan, E. Malone, J. Wu, L. N. Girardi, L. J. Bonassar, H. Lipson, C. C. Chu, J. T. Butcher, Biofabrication 2012, 4, 035005.

[13] a) Y. Lu, D. Wang, T. Li, X. Zhao, Y. Cao, H. Yang, Y. Y. Duan, Biomaterials 2009, 30, 4143; b) T. Ekblad, G. Bergström, T. Ederth, S. L. Conlan, R. Mutton, A. S. Clare, S. Wang, Y. Liu, Q. Zhao, F. D’Souza, G. T. Donnelly, P. R. Willemsen, M. E. Pettitt, M. E. Callow, J. A. Callow, B. Liedberg, Biomacromolecules 2008, 9, 2775.

[14] M. Guvendiren, H. D. Lu, J. A. Burdick, Soft Matter 2012, 8, 260.

[15] L. Yu, J. Ding, Chem. Soc. Rev. 2008, 37, 1473.

[16] a) K. R. Kamath, K. Park, Adv. Drug Delivery Rev. 1993, 11, 59; b) P. M. Kharkar, K. L. Kiick, A. M. Kloxin, Chem. Soc. Rev. 2013, 42, 7335. 


\section{WILEY-VCH}

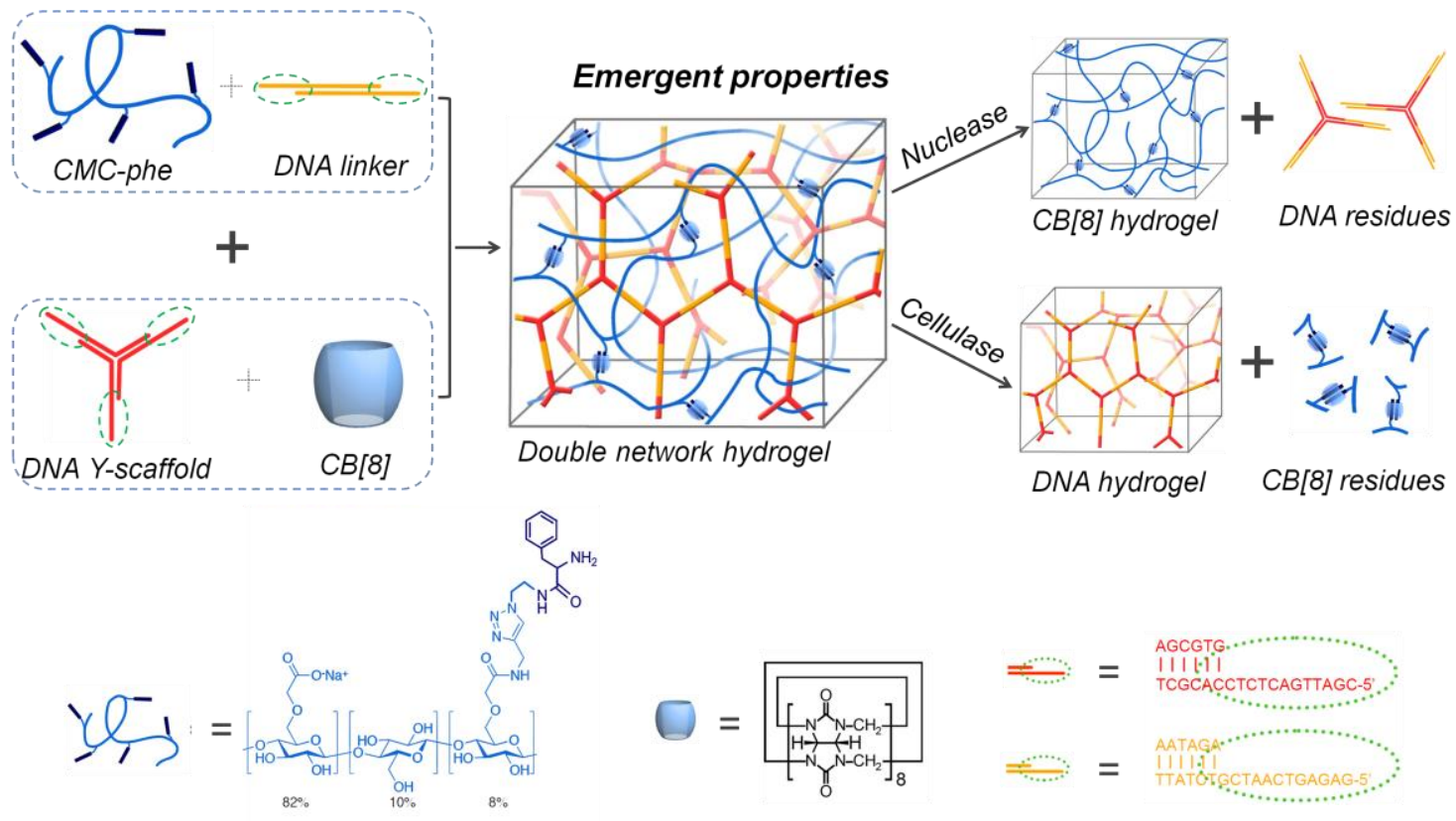

Figure 1. The formation process of double network hydrogels through supramolecular interactions. 2:1 homoternary complexation of Phe units pendant from carboxymethyl cellulose to $\mathrm{CB}[8]$ affords one macroscopic network. A second network is cross-linked by hybridization of DNA "sticky ends". The resulting double network hydrogel possesses combined properties of each single network hydrogel, such as greater mechanical strength and stimuli-responsiveness.

(A)

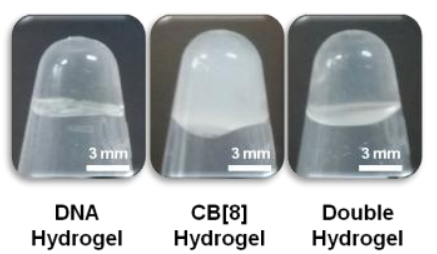

(C)

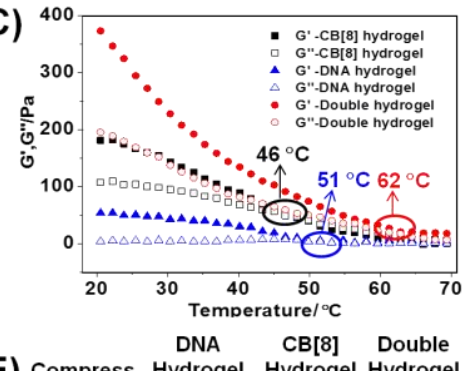

(E)

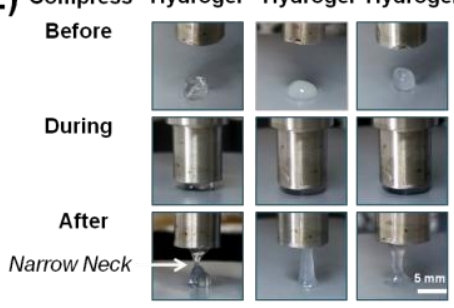

(B)

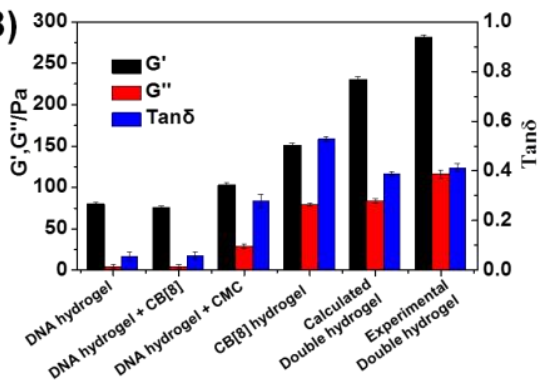

(D)

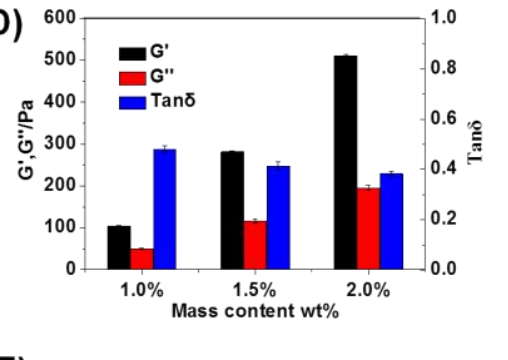

( $F)$

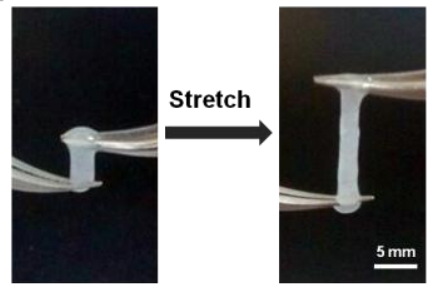




\section{WILEY-VCH}

Figure 2. Formation and characterization of the single/double network hydrogel formulation. (A) Images of $1.5 \mathrm{wt} \%$ single network hydrogels (CB[8] hydrogel and DNA hydrogel) and corresponding double network hydrogel. (B) Rheological characterization of the single/double network hydrogels. Average G', G' and $\tan \delta$ values were recorded at a fixed frequency $(1 \mathrm{~Hz})$ and strain $(1 \%)$ at $25{ }^{\circ} \mathrm{C}$ across a period of 5 minutes. (C) $1.5 \mathrm{wt} \%$ hydrogels were characterized by temperature-ramp rheological analysis, from 20 to $70{ }^{\circ} \mathrm{C}$, temperature ramp rate of $2{ }^{\circ} \mathrm{C} \mathrm{min}^{-1}$, fixed frequency $(1 \mathrm{~Hz})$ and strain $(1 \%)$. (D) Mechanical strength and $\tan \delta$ $\left(G^{\prime \prime} / G^{\prime}\right)$ of double network hydrogels with different mass contents from 1.0 to $2.0 \mathrm{wt} \%$. (E) During the rheological test, the double network hydrogel and CB[8] hydrogel exhibit a degree of stretchability, the DNA hydrogel cannot withstand the same process and appears to begin breaking. (F) The stretching process of double network hydrogel, whereby $40 \mu \mathrm{L}$ of material can be stretched as long as $2 \mathrm{~cm}$.

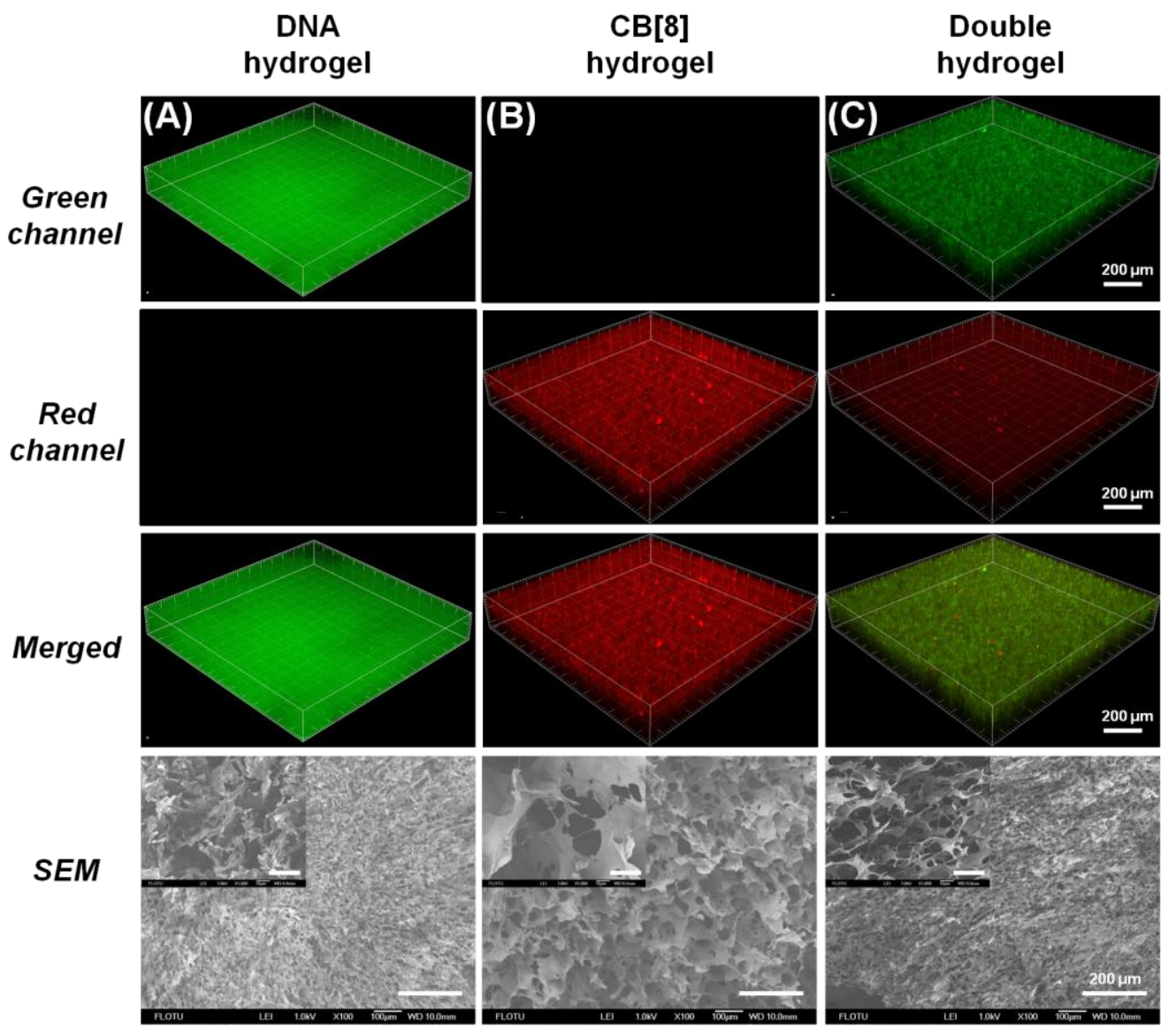

Figure 3. 3D confocal imaging of fluorescently stained hydrogel formulations. (A) DNA hydrogels were labeled with GelGreen ${ }^{\mathrm{TM}}$ and showed green color under fluorescence confocal microscopy. (B) $\mathrm{CB}[8]$ hydrogels were covalently labeled with rhodamine isothiocyanate, which exhibited red. (C) Double network hydrogels appear as intermediate "orange" under the merged views of the green and red channels. Upon combining the DNA and CB[8] hydrogels, the two networks appear to be interpenetrating. The bottom row is the scanning electron microscopy (SEM) images of lyophilized $1.5 \mathrm{wt} \%$ hydrogel samples. 
(A)

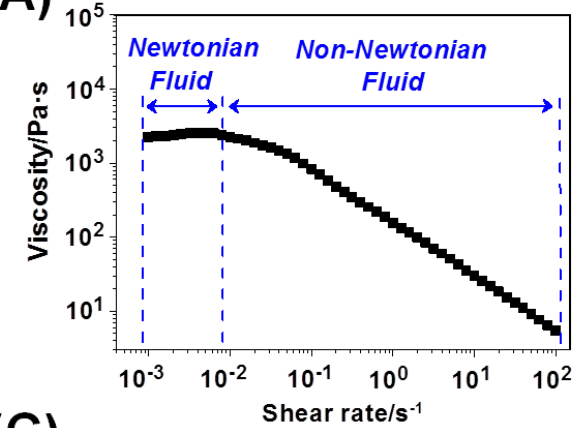

(C)

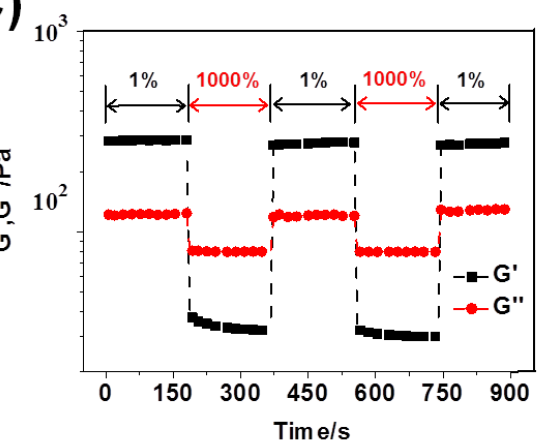

(B)

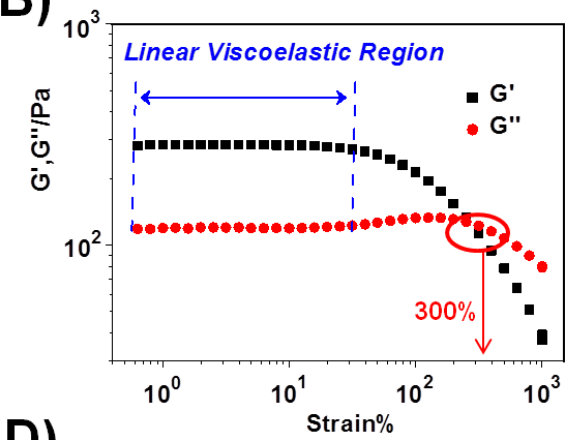

(D)

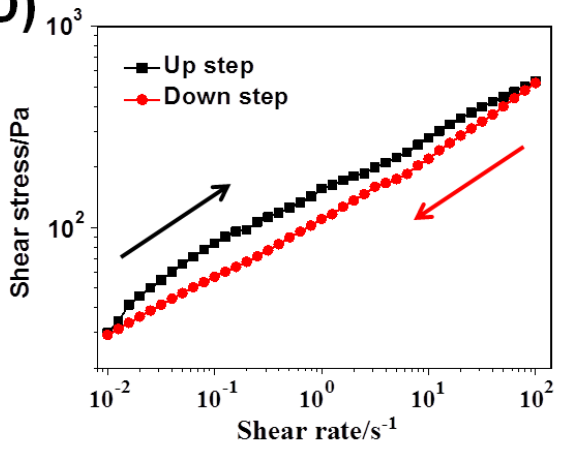

Figure 4. Shear-thinning and thixotropic properties of the double network hydrogel formulations (with each corresponding single network hydrogel of $1.5 \mathrm{wt} \%$ ). (A) Flow sweep was performed at $25{ }^{\circ} \mathrm{C}$ with shear rate varying from 0.001 to $100 \mathrm{~s}^{-1}$. (B) Rheological strain sweep was performed from 0.5 to $1000 \%$ at $25^{\circ} \mathrm{C}$ with a fixed frequency of $1 \mathrm{~Hz}$. (C) Time scan tests were performed with an alternating strain of 1 and $1000 \%$ with a fixed frequency (1 $\mathrm{Hz}$ ) at $25^{\circ} \mathrm{C}$ for $3 \mathrm{~min}$. (D) Thixotropic loop was characterized with an increasing shear rate from 0.01 to $100 \mathrm{~s}^{-1}$ and a decreasing shear rate from 100 to $0.01 \mathrm{~s}^{-1}$ at $25^{\circ} \mathrm{C}$.

(A)

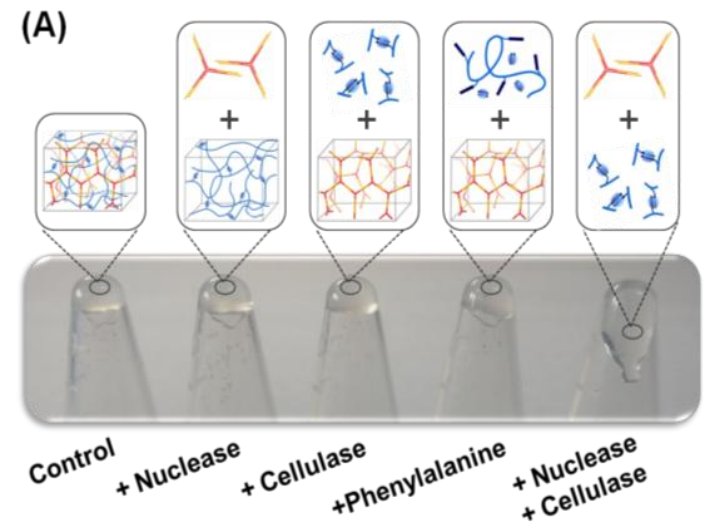

(B)

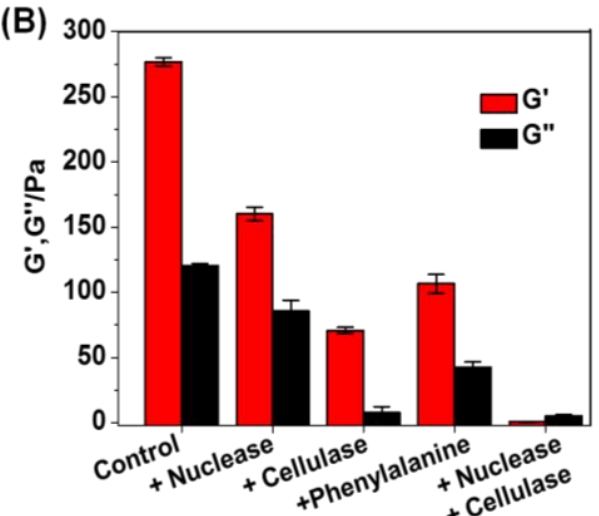

Figure 5. (A) Multiple degradation studies of the double network hydrogels: nuclease can digest the DNA hydrogel networks; cellulase can attack the cellulose backbone; phenylalanine competes for the $\mathrm{CB}[8]$ in the double network. (B) Mechanical properties of $1.5 \mathrm{wt} \%$ double network hydrogels before and after digestion by cellulase and/or nuclease or competition for $\mathrm{CB}[8]$ with free phenylalanine were characterized by time scan tests, which were performed at a fixed frequency $(1 \mathrm{~Hz})$ and strain $(1 \%)$ at $25{ }^{\circ} \mathrm{C}$ for $3 \mathrm{~min}$. 


\section{WILEY-VCH}

A supramolecular double network hydrogel is presented here by physical interpenetration of DNA and $\mathrm{CB}[8]$ networks. In addition to exhibiting an increase in strength and thermal stability, the double network hydrogel possesses excellent properties such as stretchability, ductility, shear-thinning and thixotropy. Moreover, it is enzymatically responsive to both nuclease and cellulase as well as small molecules, showing great potential as a new soft material scaffold.

Keyword: supramolecular double-network, stimuli-responsive, DNA, CB[8], hydrogels

Chuang Li,$^{\dagger \S}$ Matthew J. Rowland,${ }^{\ddagger}$ Yu Shao,${ }^{\dagger}$ Tianyang Cao,${ }^{\dagger}$ Chun Chen, ${ }^{\dagger}$ Haoyang Jia,${ }^{\dagger}$ $\mathrm{Xu}$ Zhou, ${ }^{\dagger}$ Zhongqiang Yang, ${ }^{\dagger}$ Oren A. Scherman ${ }^{* \dagger}$ and Dongsheng Liu ${ }^{* \dagger}$

Responsive double network hydrogels of interpenetrating DNA and CB[8] host-guest supramolecular systems

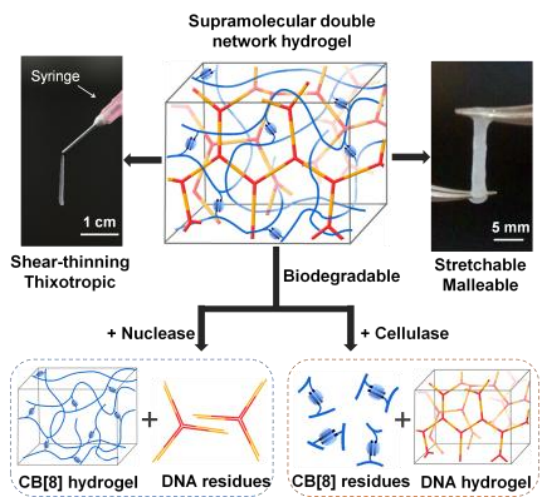




\section{WILEY-VCH}

\section{Supporting Information}

\section{Responsive double network hydrogels of interpenetrating DNA and CB[8] host-guest supramolecular systems}

Chuang Li, ${ }^{\dagger \xi}$ Matthew J. Rowland, ${ }^{\ddagger \S}$ Yu Shao, ${ }^{\dagger}$ Tianyang Cao, ${ }^{\dagger}$ Chun Chen, ${ }^{\dagger}$ Haoyang Jia,$^{\dagger}$ Xu Zhou,,$^{\dagger}$ Zhongqiang Yang, ${ }^{\dagger}$ Oren A. Scherman ${ }^{*+}$ and Dongsheng Liu ${ }^{* \dagger}$

\section{Materials}

All oligonucleotides (see Table S1) were synthesized using ABI 394 DNA synthesizer with a standard phosphoramidite DNA synthesis protocol and purified by HPLC using water/ acetonitrile/TEAA (triethylamine acetate buffer, $100 \mathrm{mM}, \mathrm{pH} 7.0$ ) as eluent. The EcoR I restriction enzyme was purchased from the TaKaRa Biotech company (Dalian, China). The Cellulase was purchased from Sigma-Aldrich. GelGreen ${ }^{\mathrm{TM}}$ (nucleic acid stain, $10000 \times$, in water) was purchased from Biotium Company (USA). Water used in all experiments was Millipore Milli-Q deionized (18.2 $\left.\mathrm{M} \Omega \mathrm{cm}^{-1}\right) .{ }^{1} \mathrm{H}-\mathrm{NMR}(500 \mathrm{MHz})$ spectra were recorded using a Bruker Avance 500 Cryo Ultrashield. Chemical shifts are measured in ppm $(\delta)$ in $\mathrm{CDCl}_{3}$ and $\mathrm{D}_{2} \mathrm{O}$ with the internal references set to $\delta 7.26 \mathrm{ppm}$ and $4.79 \mathrm{ppm}$ respectively. ${ }^{13} \mathrm{C}$ NMR (125 MHz) was recorded in $\mathrm{D}_{2} \mathrm{O}$. ATR FT-IR spectroscopy was performed using a Perkin Elmer Spectrum 100 series FT-IR spectrometer equipped with a universal ATR sampling accessory. High resolution mass spectrometry was recorded using a Waters LCT ESI. Dialysis of the CMC derived polymers was carried out by placing the reaction solutions into a dialysis tube (Spectrum Labs, Spectra/Por, standard grade regenerated cellulose dialysis membrane 6, MWCO 2000 Daltons) which was subsequently submerged in appropriate aqueous solutions. The external solutions were stirred at room temperature and replaced periodically over a 24 hour time periods ( $c a$. 4-5 times). The dialysed polymer solution was then transferred into a round bottom flask, frozen with liquid nitrogen and then lyophilized 


\section{WILEY-VCH}

overnight using a VirTis BenchTop Freeze Dryer to yield fluffy solid materials. All chemicals were purchased with reagent grade or better and used as received.

Table S1 DNA sequences of DNA hydrogel formulation.

\begin{tabular}{|l|l|}
\hline Name & Detailed sequence information \\
\hline Y1 & 5'-CGATTGACTCTCCACGCTGTCCTAACCATGACCGTCGAAG-3' \\
\hline Y2 & 5'-CGATTGACTCTCCTTCGACGGTCATGTACTAGATCAGAGG-3' \\
\hline Y3 & 5'-CGATTGACTCTCCCTCTGATCTAGTAGTTAGGACAGCGTG-3' \\
\hline L1 & 5'-GAGAGTCAATCGTCTATTCGCATGAGAATTCCATTCACCGTAAG-3' \\
\hline L2 & 5'-GAGAGTCAATCGCTTACGGTGAATGGAATTCTCATGCGAATAGA-3' \\
\hline
\end{tabular}

Red colored sequences are "sticky ends"; Green colored sequences are restriction enzyme recognition sites (GAATTC for EcoR I).

\section{Experimental Section}

\section{Synthesis of 2-azidoethanamine, 1}<smiles>NCCN</smiles>

Procedure adapted from literature. ${ }^{1}$ Sodium azide $(11.0 \mathrm{~g}, 169.23 \mathrm{mmol})$ and 2bromoethylamine hydrobromide $(10.0 \mathrm{~g}, 48.81 \mathrm{mmol})$ dissolved in water $(150 \mathrm{~mL})$ and stirred at $75{ }^{\circ} \mathrm{C}$ for 18 hours. The reaction was allowed to cool to room temperature and then diluted with $10 \% \mathrm{NaOH}$ solution $(100 \mathrm{~mL})$ and the product extracted into diethyl ether $(3 \mathrm{x} 100 \mathrm{~mL})$. The combined organic extracts were dried with magnesium sulfate, filtered and concentrated in vacuo yielding a volatile yellow oil $(3.467 \mathrm{~g}, 82 \%)$. The product was used without any further purification. ${ }^{1} \mathrm{H}-\mathrm{NMR}$ Spectroscopy $\left(\mathrm{CDCl}_{3}, 500 \mathrm{MHz}\right) \delta(\mathrm{ppm})=3.35-3.26(2 \mathrm{H}, \mathrm{t}, J$ $\left.=5.6 \mathrm{~Hz}, \mathrm{CH}_{2}\right), 2.88-2.75\left(2 \mathrm{H}, \mathrm{t}, J=5.6 \mathrm{~Hz}, \mathrm{CH}_{2}\right)$. FT-IR (ATR) $v=3366$ (br), $2104(\mathrm{~s})$. 


\section{WILEY-VCH}

\section{Synthesis of 2-amino- $N$-(2-azidoethyl)-3-phenylpropanamide hydrochloride, 2}<smiles>NCCNC(=O)C(N)Cc1ccccc1</smiles>

To a cooled solution $\left(\sim 0{ }^{\circ} \mathrm{C}\right)$ of $1(1.69 \mathrm{~g}, 19.6 \mathrm{mmol})$ in DMF (200 mL) was added triethylamine $(2.72 \mathrm{~mL}, 19.6 \mathrm{mmol})$ followed by Boc-Phe-OSu (7.115 g, $19.6 \mathrm{mmol})$. The reaction was allowed to warm to room temperature and stirred over a period of 18 hours. The reaction was then quenched with cold water and the product extracted into ethyl acetate (200 $\mathrm{mL})$. The organic layer was washed with water $(3 \times 500 \mathrm{~mL})$ and dried with magnesium sulfate, filtered and concentrated in vacuo yielding a white solid (2.545 g). This solid was dissolved in a minimal amount of diethyl ether and $2 \mathrm{M}$ hydrogen chloride in diethyl ether (15 $\mathrm{mL}$ ) was added. The reaction was stirred for 4 hours and concentrated in vacuo to yield a yellow solid. The crude product was then triturated in diethyl ether and a white precipitate was collected by vacuum filtration as the product 2 in $\mathrm{HCl}$ salt form $(1.625 \mathrm{~g}, 31 \%)$ and used without further purification. ${ }^{1} \mathrm{H}-\mathrm{NMR}$ Spectroscopy $\left(\mathrm{D}_{2} \mathrm{O}, 500 \mathrm{MHz}\right) \delta(\mathrm{ppm})=7.40-7.20$ $(5 \mathrm{H}, \mathrm{m}, \mathrm{Ar}-\mathrm{H}), 4.14-4.08(1 \mathrm{H}, \mathrm{t}, \mathrm{J}=7.1, \mathrm{CH}), 3.35-3.06(6 \mathrm{H}, \mathrm{m}, \mathrm{CH})^{2}{ }^{13} \mathrm{C}-\mathrm{NMR}$ Spectroscopy $\left(\mathrm{D}_{2} \mathrm{O}, 125 \mathrm{MHz}\right) \delta(\mathrm{ppm})=169.11(\mathrm{CO}), 133.75(\mathrm{ArC}), 129.34(\mathrm{ArCH}), 129.10$ (ArCH), $127.97(\mathrm{ArCH}), 54.52(\mathrm{CH}), 49.68\left(\mathrm{CH}_{2}\right), 38.47\left(\mathrm{CH}_{2}\right), 36.83\left(\mathrm{CH}_{2}\right)$. HRMS: Found 234.1360 $\left[\mathrm{C}_{11} \mathrm{H}_{16} \mathrm{~N}_{5} \mathrm{O}\right]^{+}$calculated 234.1355. FTIR (ATR) $v=3324$ (m), 2868 (br), 2105 (s), $1652(\mathrm{~s}), 1566(\mathrm{~s}), 1485(\mathrm{~s})$.

\section{Synthesis of propargyl-CMC, 3}




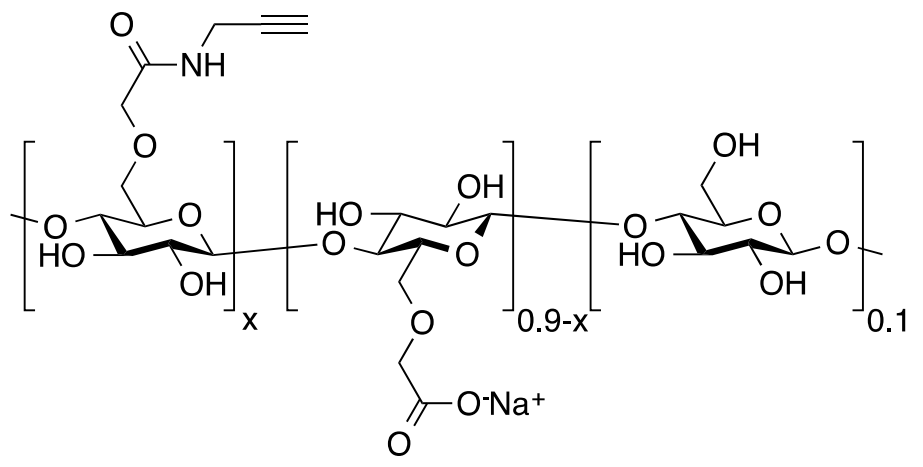

Sodium carboxymethylcellulose (3.560 g, average molecular weight 700,000 Da), was added slowly to vigorously stirring $\mathrm{pH} 4$ buffer $(285 \mathrm{~mL})$ and stirred for several hours until completely dissolved. $N$-hydroxysuccinimide (3.33 g, $28.96 \mathrm{mmol})$ was added followed by $N$ (3-dimethylaminopropyl)- $N$-ethylcarbodiimide hydrochloride (5.55 g, $28.17 \mathrm{mmol}$ ) and then propargylamine $(3.06 \mathrm{~mL}, 47.80 \mathrm{mmol})$. The reaction was stirred for 18 hours and then poured drop-wise into $3 \mathrm{~L}$ of acetone forming a white precipitate which was collected via gravity filtration, washed with further acetone, and then dried in a vacuum over at $40{ }^{\circ} \mathrm{C}$ for 24 hours. This yielded $3.860 \mathrm{~g}$ of an off-white solid that was used without further purification and characterization.

\section{Synthesis of CMC-phe, 4}

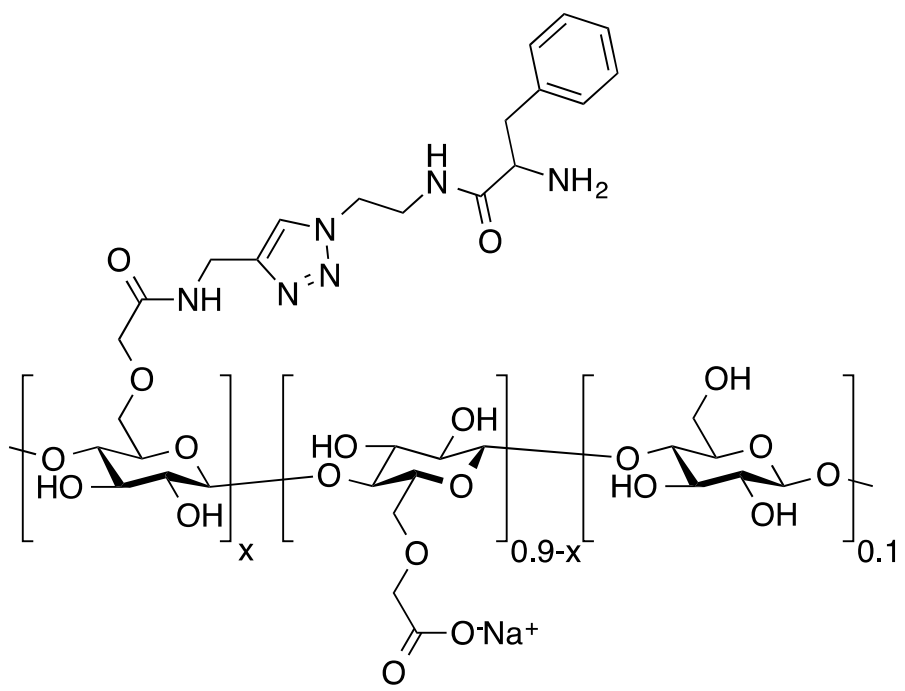




\section{WILEY-VCH}

A solution of $3(3.860 \mathrm{~g})$ was made by dissolution in water $(100 \mathrm{~mL})$ at $50{ }^{\circ} \mathrm{C}$ over several hours. Once homogeneous the solution was cooled to room temperature and diluted by slow addition of ethanol (100 mL). $2(353 \mathrm{mg}, 1.31 \mathrm{mmol})$ was added and the solution degassed with nitrogen. Separately, a solution of copper (I) bromide (188 mg, $1.31 \mathrm{mmol})$ and $N, N, N^{\prime}, N^{\prime}, N^{\prime \prime}$-pentamethyldiethylenetriamine (PMDTA, $\left.274 \mu \mathrm{L}, 1.31 \mathrm{mmol}\right)$ in water $(5 \mathrm{~mL})$ was degassed with nitrogen and then injected into the solution of $\mathbf{2}$ and $\mathbf{3}$ and stirred overnight. The reaction was then dialysed against EDTA and $\mathrm{Na}_{2} \mathrm{CO}_{3}$ solution until the blue colour diminished (around 3 days) followed by water (4 days). The dialysed product was then dried by lyophilisation and the degree of functionalisation with phenylalanine (7\% per monosaccharide) determined by ${ }^{1} \mathrm{H}-\mathrm{NMR} .2 .825 \mathrm{~g}$ of a fluffy white solid was recovered. ${ }^{1} \mathrm{H}-$ NMR Spectroscopy $\left(\mathrm{D}_{2} \mathrm{O}, 500 \mathrm{MHz}\right) \delta(\mathrm{ppm})=7.40-7.00(5 \mathrm{H}$, br, aromatic unit of phenylalanine), 4.60-2.60 (127H, br, CMC backbone and phe linking unit).

\section{Synthesis of rhodamine-labeled CMC-phe, 5}

To $4(100 \mathrm{mg})$ in water $(20 \mathrm{~mL})$ was added rhodamine B isothiocyanate $(1 \mathrm{mg})$ and dibutyltin dilaurate (catalytic amount, 1 drop). The reaction was stirred overnight and then purified by dialysis against water for one week. Product isolated by lyophilisation yielding a light pink fluffy solid.

\section{Synthesis and preparation of cucurbit[8]uril $(\mathrm{CB}[8])$}

Cucurbit[8]uril was prepared according to literature procedures. ${ }^{2}$

\section{CB [8] Hydrogel formation}

CMC-phe (15 mg, polymer 4 or 5) was dissolved in PBS buffer $(1 \mathrm{~mL})$ and stirred until homogeneous. $\mathrm{CB}[8]$ ( $3 \mathrm{mg}$ ) was added and the hydrogel formulation stirred until cloudy and 


\section{WILEY-VCH}

the hydrogel expressed viscoelastic behavior (after roughly 1 hour).

\section{DNA hydrogel preparation}

A stock solution of Y-scaffold $(2 \mathrm{mM})$ and linker $(3 \mathrm{mM})$ were prepared respectively in phosphate buffer (100 mM, pH 7.4) following the established protocol. For preparation of 1.5 wt\% DNA hydrogel with $100 \mu \mathrm{l}$, Y-scaffold $(2 \mathrm{mM}, 9.7 \mu \mathrm{L})$ and DNA linker (3 mM, $9.7 \mu \mathrm{L})$ were mixed together in phosphate buffer $(400 \mathrm{mM}, \mathrm{pH} 7.4,25 \mu \mathrm{L})$ and water $(55.6 \mu \mathrm{L})$ in Ep tube, stirred, and left at room temperature for overnight to form the desired hydrogel.

\section{Double network hydrogel preparation}

In a typical experiment for preparation of $100 \mu \mathrm{L}$ of double network hydrogel with $1.5 \mathrm{wt} \%$ of each single network hydrogel, CMC-phe solution $(60 \mathrm{mg} / \mathrm{mL}, 25 \mu \mathrm{L})$ and DNA linker $(3 \mathrm{mM}$, $9.7 \mu \mathrm{L})$ were mixed together as component $\mathrm{A}$, whereas $\mathrm{Y}$-scaffold $(2 \mathrm{mM}, 9.7 \mu \mathrm{L})$ and $\mathrm{CB}[8]$ suspension $(12 \mathrm{mg} / \mathrm{ml}, 25 \mu \mathrm{L})$ were mixed together as component B. Component A and B were then mixed in phosphate buffer $(400 \mathrm{mM}, \mathrm{pH} 7.4,25 \mu \mathrm{L})$ and water $(5.6 \mu \mathrm{L})$ and left at room temperature for overnight to form the desired hydrogel. Double network hydrogels with different mass contents from $0.5 \mathrm{wt} \%$ to $2 \mathrm{wt} \%$ were prepared following the same protocol above.

\section{Rheological characterization}

Rheological tests were carried out on an AR-G2 rheometer (TA Instruments) equipped with a temperature controller. Four types of rheological experiments were performed in $8 \mathrm{~mm}$ parallel-plate geometry using $40 \mu \mathrm{L}$ of hydrogels (resulting in a gap size of $0.15 \mathrm{~mm}$ ): i) In order to find the linear viscoelastic region of the time sweeps, oscillatory strain sweep (0.01$1000 \%$ ) was conducted at $25^{\circ} \mathrm{C}$ with a fixed frequency of $1 \mathrm{~Hz}$; ii) Time-scan tests were 


\section{WILEY-VCH}

done at a fixed frequency and strain of $1 \mathrm{~Hz}$ and $1 \%$, respectively, at $25^{\circ} \mathrm{C}$ for $3 \mathrm{~min}$; iii) Temperature-ramp tests were performed at a fixed frequency and strain of $1 \mathrm{~Hz}$ and $1 \%$, respectively, and the changes in the shear storage modulus $\left(G^{\prime}\right)$ and shear-loss modulus $\left(G^{\prime \prime}\right)$ were measured from 20 to $70{ }^{\circ} \mathrm{C}$ at a rate of $2^{\circ} \mathrm{C} \mathrm{min}$; iv) Flow sweep was performed at 25 Fracture with shear rate varying from 0.001 to $100 \mathrm{~s}^{-1}$.

\section{Confocal laser-scanning microscopy imaging}

Double network hydrogel stained with GelGreen ${ }^{\mathrm{TM}}$ or/and modified with rhodamine isothiocyanate was characterized using Confocal laser-scanning microscopy (Zeiss, LSM780) with excitation wavelength of $488 \mathrm{~nm}$ or/and $540 \mathrm{~nm}$.

\section{Enzymatic digestion}

For partially degraded, double network hydrogel $(30 \mu \mathrm{L}$, with $2.0 \mathrm{wt} \%$ of each single network

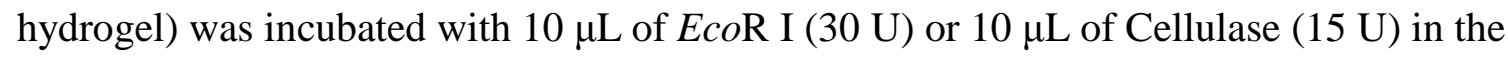
corresponding reaction buffer at room temperature for $24 \mathrm{~h}$, resulting in $40 \mu \mathrm{L}$ of hydrogel with $1.5 \mathrm{wt} \%$ of each single network hydrogel, followed with characterization by rheological time-scan for $5 \mathrm{~min}$ at a fixed frequency of $1 \mathrm{~Hz}$ and strain of $1 \%$.

For fully degraded, both $10 \mu \mathrm{L}$ of EcoR I (30 U) and $10 \mu \mathrm{L}$ of Cellulase (15 U) in the corresponding reaction buffer were added into the double network hydrogel ( $20 \mu \mathrm{L}$, with 3.0 wt $\%$ of each single network hydrogel), resulting in $40 \mu \mathrm{L}$ of hydrogel with $1.5 \mathrm{wt} \%$ of each single network hydrogel, followed with characterization by rheological time-scan for 5 min at a fixed frequency of $1 \mathrm{~Hz}$ and strain of $1 \%$.

\section{Penylalanine competitive replace}

Double network hydrogel (30 $\mu \mathrm{L}$, with $2.0 \mathrm{wt} \%$ of each single network hydrogel) was incubated with $10 \mu \mathrm{L}$ of L-phenylalanine $(10 \mathrm{mg} / \mathrm{ml}, 10 \mu \mathrm{L})$ in phosphate buffer $(100 \mathrm{mM}$, 


\section{WILEY-VCH}

$\mathrm{pH}$ 7.4) at room temperature for $24 \mathrm{~h}$, resulting in $40 \mu \mathrm{L}$ of hydrogel with $1.5 \mathrm{wt} \%$ of each single network hydrogel, followed with characterization by rheological time-scan for 5 min at a fixed frequency of $1 \mathrm{~Hz}$ and strain of $1 \%$.

\section{Supplementary figures}

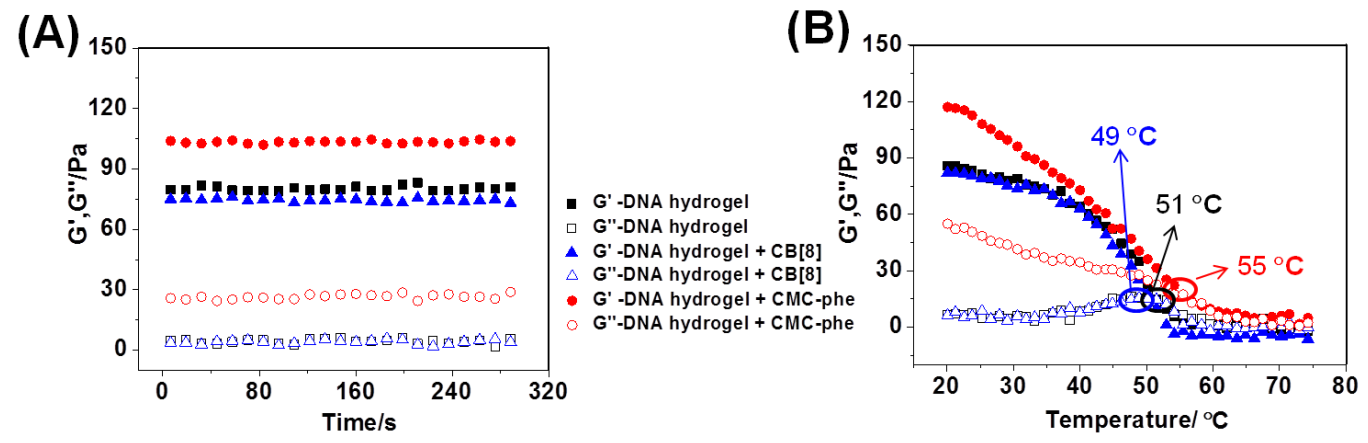

Figure S1 Mechanical characterization of DNA hydrogels (1.5 wt\%) with addition of CMCphe or $\mathrm{CB}[8]$. (A) Time sweep was performed at a fixed frequency and strain of $1 \mathrm{~Hz}$ and $1 \%$ at $25^{\circ} \mathrm{C}$. (B) Temperature ramp was performed from 20 to $70{ }^{\circ} \mathrm{C}$ at a rate of $2{ }^{\circ} \mathrm{C} \mathrm{min}{ }^{-1}$ with a fixed frequency and strain of $1 \mathrm{~Hz}$ and $1 \%$.

(A)

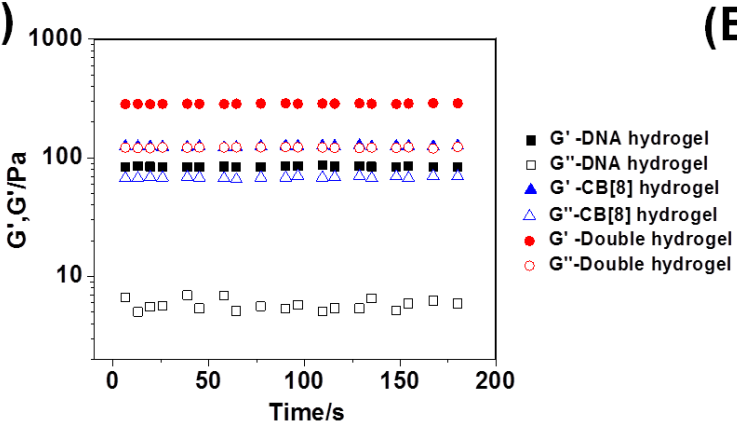

(B)

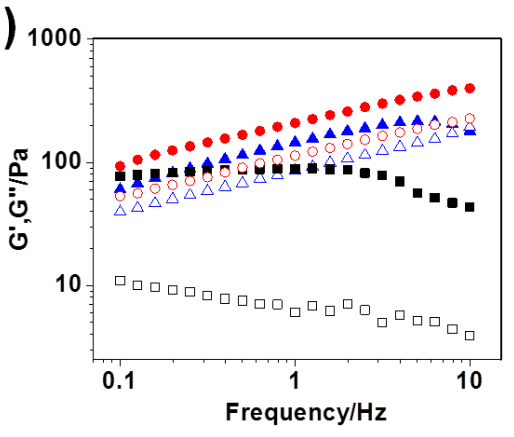

Figure S2 Mechanical characterization of hydrogels (with $1.5 \mathrm{wt} \%$ of each single network hydrogel). (A) Time sweep was performed at a fixed frequency and strain of $1 \mathrm{~Hz}$ and $1 \%$ at $25^{\circ} \mathrm{C}$. (B) Frequency sweep was carried out from 0.1 to $10 \mathrm{~Hz}$ at $25^{\circ} \mathrm{C}$ with a fixed strain of $1 \%$. 
Figure S3 DNA hydrogel (1.5 wt\%) was manipulated with tweezers. Due to the brittleness,

DNA hydrogel turned out narrow neck followed by fracture when stretched.

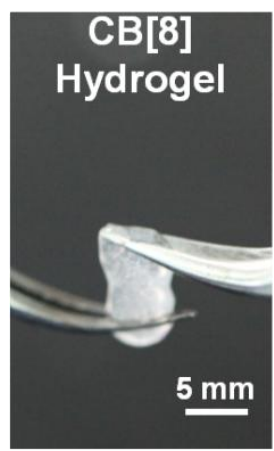

\section{Stretch}

Figure S4 CB[8] hydrogel (1.5 wt\%) was manipulated with tweezers which can be stretched to a line with a $2 \mathrm{~cm}$ length.

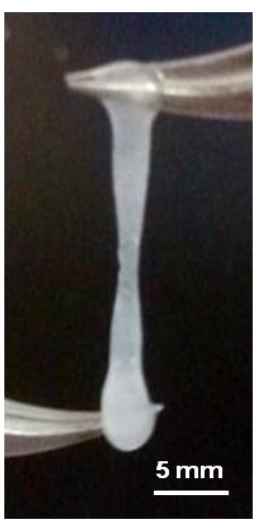

Figure S5 Double network hydrogel (1.5 wt\%) can be stretched as long as $3 \mathrm{~cm}$ before fracture. 


\section{WILEY-VCH}
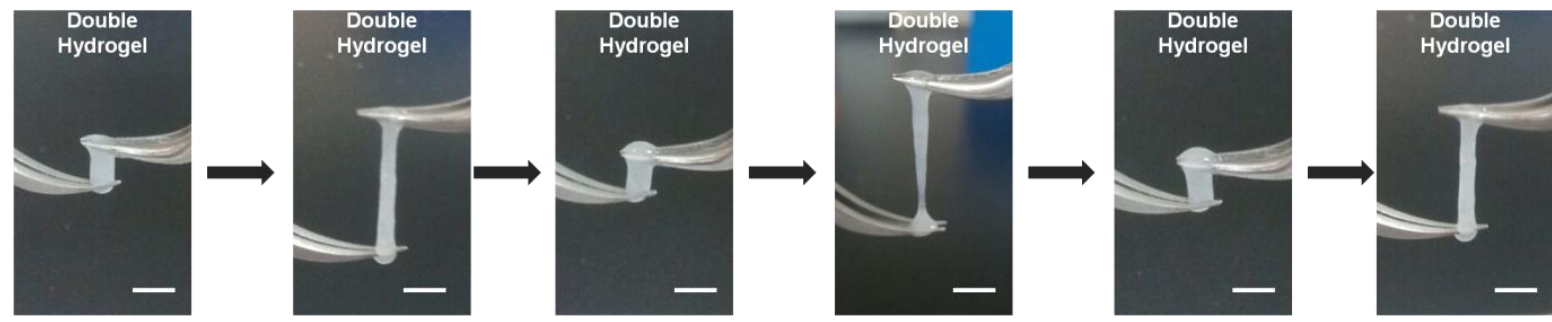

Figure S6 Double network hydrogel can be compressed or stretched and the process can be

cycles for three times with good reversibility. Scale bar is $5 \mathrm{~mm}$.
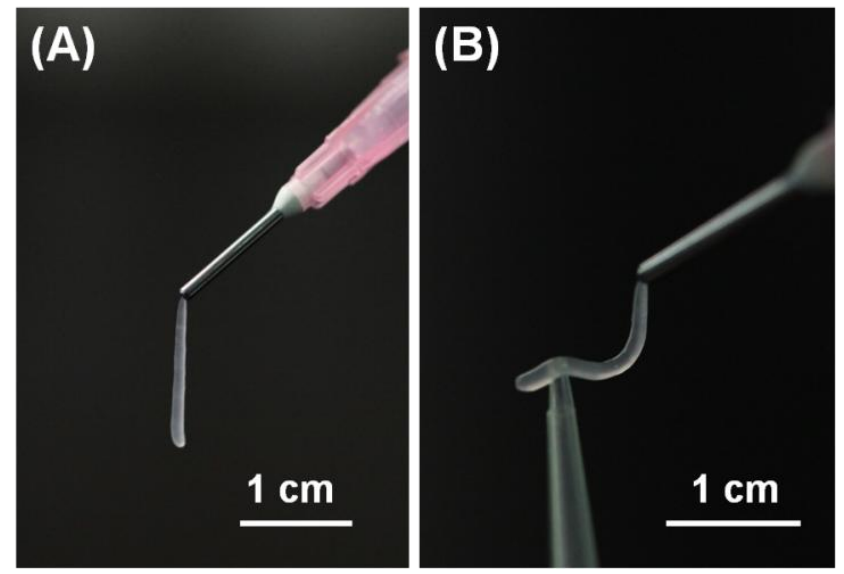

Figure S7 Double network hydrogel $(1.5 \mathrm{wt} \%)$ can be directly injected through a needle and syringe to form a hydrogel line (A) which could be bent and twisted (B), demonstrating it has excellent shear thinning and rapid thixotropic properties.

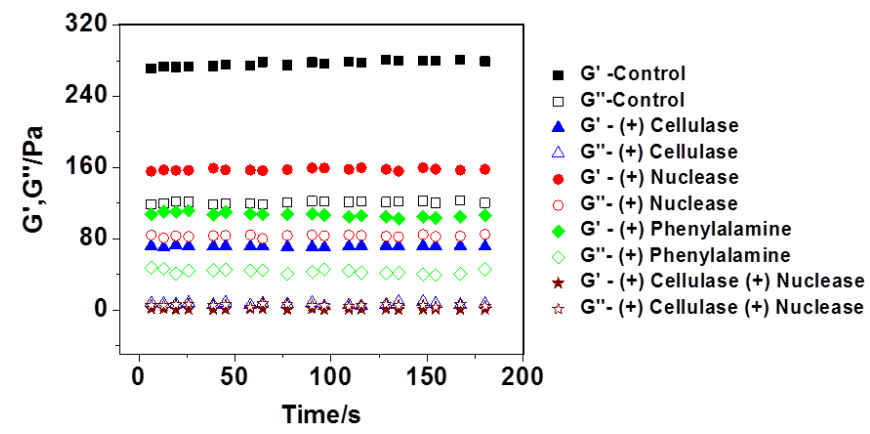

Figure S8 Mechanical characterization of double network hydrogels (1.5 wt $\%)$ with enzymatic digestion or competitive replace by phenylalanine.

\section{References}




\section{WILEY-VCH}

1. I. A. Inverarity, A. N. Hulme, Org. Biomol. Chem., 2007, 5, 636-643.

1

2

3

4

5

2. J. Kim, I. S. Jung, S. Y. Kim, E. Lee, J. K. Kang, S. Sakamoto, K. Yamaguchi, K. Kim, J. Am. Chem. Soc., 2000, 122, 540-541. 
Click here to download Production Data: Production Data.rar 